\title{
Conflicting logics of public relations in the English NHS: a qualitative study of communications and engagement
}

\begin{tabular}{|c|c|}
\hline Journal: & Sociological Research Online \\
\hline Manuscript ID & SRO-18-0008.R2 \\
\hline Manuscript Type: & Original Manuscript \\
\hline Keywords: & $\begin{array}{l}\text { marketing, citizen, engagement, participation, health service, } \\
\text { communication }\end{array}$ \\
\hline Abstract: & $\begin{array}{l}\text { Since the formation of the NHS, all UK citizens have been entitled to } \\
\text { access a universal health service, but radical changes to the NHS are } \\
\text { now occurring. Although recent NHS policy claims that 'the NHS belongs } \\
\text { to us all' and 'the NHS is a social movement', these collectivist rhetorical } \\
\text { claims appear when such communitarian discourse is under threat, as } \\
\text { NHS England's (2014) Five Year Forward View tries to square the circle } \\
\text { of efficiency, quality and equity. Historically, patients and user-groups } \\
\text { have formed support networks and social movements, and collectively } \\
\text { campaigned for their voices to be heard by policy makers, clinicians and } \\
\text { managers. In contrast to the discourse of user movements, the field of } \\
\text { marketing and public relations generally relies on the idea of the public } \\
\text { as consumers rather than citizens. As complex governance arrangements } \\
\text { blur the lines between public and private, concerns have been raised } \\
\text { about how 'spin' associated with public relations might contravene } \\
\text { accountability, communicative rationality and deliberative or } \\
\text { participatory democracy. Using qualitative methods, we conducted } \\
\text { empirical research in two localities to explore the role of communications } \\
\text { and engagement staff as they worked to 'transform' the NHS in line with } \\
\text { the vision of the Five Year Forward View. We gathered documentary data } \\
\text { and interview data from people whose roles required them to 'do } \\
\text { engagement'. These staff came from a range of backgrounds, including } \\
\text { professional marketing backgrounds, and many were unaware of } \\
\text { emancipatory goals or user-led involvement and activism. Our analysis } \\
\text { examines the competing logics of marketing and patient empowerment } \\
\text { within a key stakeholder matrix document and that surfaced in } \\
\text { participants' accounts of their engagement practices. }\end{array}$ \\
\hline
\end{tabular}

\section{SCHOLARONE" Manuscripts}




\title{
Conflicting logics of public relations in the English NHS: a qualitative study of communications and engagement
}

\begin{abstract}
Since the formation of the NHS, all UK citizens have been entitled to access a universal health service, but radical changes to the NHS are now occurring. Although recent NHS policy claims that 'the NHS belongs to us all' and 'the NHS is a social movement', these collectivist rhetorical claims appear when such communitarian discourse is under threat, as NHS England's (2014) Five Year Forward View tries to square the circle of efficiency, quality and equity. Historically, patients and user-groups have formed support networks and social movements, and collectively campaigned for their voices to be heard by policy makers, clinicians and managers. In contrast to the discourse of user movements, the field of marketing and public relations generally relies on the idea of the public as consumers rather than citizens. As complex governance arrangements blur the lines between public and private, concerns have been raised about how 'spin' associated with public relations might contravene accountability, communicative rationality and deliberative or participatory democracy. Using qualitative methods, we conducted empirical research in two localities to explore the role of communications and engagement staff as they worked to 'transform' the NHS in line with the vision of the Five Year Forward View. We gathered documentary data and interview data from people whose roles required them to 'do engagement'. These staff came from a range of backgrounds, including professional marketing backgrounds, and many were unaware of emancipatory goals or user-led involvement and activism. Our analysis examines the competing logics of marketing and patient empowerment within a key stakeholder matrix document and that surfaced in participants' accounts of their engagement practices.
\end{abstract}

Keywords: marketing, citizen, engagement, participation, health service, communication Introduction

This article builds on the notion of health citizenship (Komporozos et al, 2016) and offers new insights into how citizens are engaged with by health services' (and partner organisations' such as local authorities) public communications and engagement functions. Two different 
trajectories, cultures or 'logics' of participation emanate from distinct origins in a) the field of business-oriented marketing and b) more emancipatory, socially conscious movements (Gibson et al., 2012, Moor, 2011). Traditionally separate in terms of academic disciplines, and often conceptualised as antithetical, we seek to understand how these logics might influence engagement practices and thus how various forms of health citizenship are configured.

Public relations or PR has acquired negative connotations of 'spin', which we define as distorted communication (Peters, 2016, Moloney, 2006, Gewirtz et al, 2004). In a 'post-truth age' (Madden and Speed, 2017), suspicion of the language used by powerful elites presumes that such communication serves vested interests; these critiques are supported by academic work on discourse, knowledge and power (Fairclough, 2003). However, accusations of 'cultural snobbery' have been levelled at academics by Moloney (2006, p.3) who argues that 'UK academic literature in sociology, communications, media and political studies does not pay enough attention to public relations as a subject worth critical attention in its own right'. Moloney (2006) engages extensively with ethical issues of politics, policy, democracy and propaganda or 'spin'. Similarly, Barnett and Mahoney (2016) argue for recognition and greater critical analysis of the use of customer relationship management techniques within the public sector. The influence of business marketing on the public sector has been traced back as far as 1969 (Cole and Cotterill, 2005), and the question of whether marketing is appropriate at all in the public sector, and whether commercialism detracts from a public service ethic, has been posed in relation to the NHS Citizen's Charter (Walsh, 1994). More recently, Moor (2011) provides a history of social marketing in health and healthcare and associated ethical problems, demonstrating how social marketing has come to occupy a formal role in government health policy. Part of our aim here is to urge scholars with an interest in contemporary health service communications to pay attention to studies of public relations that usefully engage with critical theory (L'Etang et al, 2016).

Academic study of patient and public involvement (PPI) in health research, health service delivery and public participation more generally has extensively debated issues of voice, choice and, more recently, co-production (Author B et al., 2015, Bovaird and Loeffler, 2012). However, we have not found any previous instances of research that studies what it is that NHS communications and engagement staff do when they do 'engagement', how they conceptualise 
their work, and where their understandings might diverge from participatory and emancipatory discourses associated with dialogue and the public realm. Our aim is to fill this gap.

Despite scepticism about PR, communications, discursive representation and ideological attacks that undermine the traditional role of public services; efforts are being made by public sector organisations to involve the public as partners in decision making (Komporozos-Athanasiou et al, 2018, Author C et al., 2018, Hudson, 2017). This holds the potential to reduce barriers between elites and patients and the public, and even up power imbalances. Such involvement is often based on a deliberative logic that holds that consensus is possible and should be the ultimate purpose of public deliberation (Habermas, 1989; Newman 2001; Author B et al., 2015; Author $C$ 2012). A seminal text that analyses participation from a rather different perspective is Arnstein's (1969) ladder of participation, where participation is rooted more in agonistic pluralism (Mouffe, 1999; Ramsey, 2016). Arnstein's analysis of 'non-participation', based on manipulation and therapy, foreshadows critiques of PPI as 'tick-boxing' and 'tokenism'. Although there have been critiques of Arnstein's ladder (Tritter and McCallum, 2006, Madden and Speed, 2017), Arnstein's original article has been very extensively cited by academics and appears (albeit in truncated form) in NHS England guidance (NHS England undated a).

In contrast to the American context in which Arnstein constructed her ladder, the establishment of the tax-funded NHS did largely take health out of the market and provide citizens with universal entitlement to free health care in the UK. Nationally, accountability to the public was deemed to be via the ballot box, while individual patients' interests were often assumed to be best represented by the medical profession. Historically, patient and user-groups have formed as support groups and social movements and collectively campaigned for their voice to be heard by clinicians and policy makers (Hogg, 2008, Baggott, 2013, Author C et al., 2017). In 2013 NHS England published 'A Call to Action'. This document claims that 'the NHS belongs to us all' and 'the NHS is a social movement' (NHS England 2013a), acknowledging the public's legitimate right to a say in planning and decision making. These rhetorical claims, which invoke a logic of social justice and emancipation, appear when such communitarian discourse appears to be threatened, as NHS England's (2014) Five Year Forward View tries to square the circle of efficiency, quality and equity, in a context of straitened funding for public services, and amidst claims from some quarters that these efforts are a fig leaf for moves to reduce public funding for 
the NHS, or even privatise aspects of healthcare provision (e.g. Hunter, 2016). Academic research has until recently adopted the label of PPI (patient and public involvement) but the term engagement is now common in NHS policy documents and is used by practitioners and so it seems vital to understand how engagement is currently being practised.

Policy context

Involving patients and the public has for some time been a statutory requirement of NHS organisations, particularly in relation to major service change (NHS England, 2013b). The Francis Inquiry (2013) into failings of care at Stafford Hospital insisted that the voices of patients and the public should be afforded more influence. Since the Inquiry, NHS organisations have been required to demonstrate openness, transparency and dialogue with the public; this has included developing their communications teams. Putting Patients First is the title of a recent business plan published by NHS England (undated b) which uses the language of marketing by, for example, framing patients as 'customers'. The document lists 'eight key activities', including 'World class customer service: information, transparency and participation'. The plan expresses a commitment to instigate a communications infrastructure: 'We will deliver a programme of stakeholder and learning development events to share key information, motivate and engage with key audiences'. (NHS England undated b, para. 3.131).

The Francis Inquiry advocated greater clinical engagement as well as patient and public engagement (Francis 2013, Kings Fund 2012). Consequently, sections on staff and patient and public engagement now appear in annual reports and strategy documents emanating from NHS organisations. It is unclear whether this engagement imperative (James, 2013) is effective, as a problem confronting any organisation attempting to 'engage' patients and the public is that, like involvement and participation, engagement is ambiguous, multifaceted and often a contested concept (Parsons et al, 2010). Arguably, the term is an instance of 'strategic vagueness' (Potter, 1996).

Despite this policy ambiguity, in the post-Francis era, a radical transformation of the NHS is occurring (Author C et al, 2018). The NHS, similar to other Western health care services, faces challenges resulting from a changing demographic profile with people living longer and needing 
ongoing health care. At the same time new technologies and therapies have also put the health system under financial pressure. It is against this backcloth that Sustainability and Transformation Partnerships (STPs) were introduced, with the intention they would somehow resolve these challenges. NHS England has reorganised the NHS into 44 STPs, charged with implementing the Five Year Forward View in practice, managing demand for healthcare, and transforming local provision (Author $\mathrm{C}$ et al., 2018). Critics argue that STPs lack accountability to citizens; some see STPs as a fundamental neo-liberal shift in the political economy of the NHS that undermines the rights of citizens (Leys, 2017).

Evidence of patient and public participation in STPs suggests a disconnection between policy statements that advocate patient and public engagement or participation and the actual form taken by involvement and engagement on the ground (ANON, 2017, ANON, 2017). Alderwick et al $(2016$, p.58) note that:

Patients and the public have been largely absent from the planning process so far. There appear to be two main reasons for this: a lack of time for adequate engagement, and instructions from national NHS bodies to keep details of draft plans out of the public domain.

They also point out that local planning was steered forcefully by national NHS bodies:

As well as the timeline creating a barrier to meaningful public engagement, national NHS bodies had also asked STP leaders to keep details of draft STPs out of the public domain. [...] Two main reasons were given for this. The first was that national NHS leaders wanted to be able to 'manage' the STP narrative at a national level - particularly where plans might involve politically sensitive changes to hospital services. The second was that national leaders did not want draft proposals to be made public until they had agreed on their content. (Alderwick et al, 2016, p.37)

This lack of transparency contradicts principles of good governance, indicates the contentious nature of STPs and raises the question of how engagement can be expected to take place in such contradictory arenas. The intention to 'manage the narrative' contravenes the idea of activist 
forms of citizenship and raises questions concerning the role of communications and engagement teams.

To summarise, contemporary policy comprises a complex admixture of a consumerist logic that conflates patients with customers and a more participatory approach associated with voice. Voices are frequently channelled through officially sanctioned routes, such as healthcare organisations' own professionally and managerially led forums (invited spaces of governance, in the language of Barnes et al., 2007). In this article we seek to avoid well-worn debates about terminology to focus on the role of practitioners who are charged with engagement, to better understand the competing logics that inform their practices.

\section{Methods}

Our study design is inductive; the research question identified in this article emerged during reanalysis of our primary data-set. We collected qualitative data in the form of documents, observations and interviews within two regions at a time when STPs were emergent phenomena. Fieldwork was conducted in 2014-2016 during which time the lead author attended regular monthly meetings of an STP public engagement group in one of the regions that consisted of about ten members of the public, experienced in PPI and three NHS staff who were responsible for communications and engagement, as well as an NHS administrator and the STP Programme Director. The second STP did not have such a group but the lead author attended ad hoc engagement events in that locality. The sampling strategy for interviews combined purposive sampling with members of the group and more opportunistic snowball sampling whereby people with relevant job titles working in organisations affiliated to the STP were invited to participate. Documents in the form of business plans and strategies were obtained from organisations' websites or by request. Findings from the study have been published elsewhere (ANON 2018, ANON 2017, ANON, 2016); here we present novel insights based on data relating to the theme of citizenship and public relations.

For the purpose of this article, we extracted a sub-set of 14 transcripts from interviews with staff employed by NHS and local authority bodies and NHS non-executive directors, all of whom had responsibility for communications and/or engagement. Within this sample, job titles and role descriptions ranged across the fluid field of communications, participation and engagement and 
included, for example, a 'Public Participation Manager' working in a local authority, a 'Communications and Engagement Lead' based in a management office of an emergent STP, a Clinical Commissioning Group (CCG) 'Engagement Manager', a CCG 'Patient Experience and Quality Support Manager', a 'Membership Manager' based in a hospital organization, and an independent consultant. We obtained ethical permission from the Health Research Authority and we designed interview schedules to be flexible and respond to the specific situations of study participants. This enabled us to pursue themes of interest and relevance to participants, rather than insisting on our own a priori academic topics (Kvale, 2008). A key data source was a stakeholder analysis document produced by an NHS organisation in one of the regions. During our analytical discussions, we were struck by an incongruity between the use in this document of a matrix that privileges influential stakeholders, and alternative approaches that prioritise the voices of less powerful citizens and communities. We became interested in how these incongruities played out in the practices of people working in the NHS and local authorities who have some responsibility for engagement and/or participation. Interviews were fully transcribed, and we analysed this interview data using Nvivo software, coding for instances of marketing, communications, patient participation and involvement. Both the lead and last author worked on the original project. To counteract possible bias from fieldwork experience, the data collected by the lead author was subject to interpretation and critique by the last author. The second author was not part of the original study team and provided a more distant perspective. Our analysis sought not to impose a normative framework such that we might identify and evaluate 'genuine' involvement; rather we drew on literature dealing with language and discourse (Fairclough, 2003, Potter, 1996) and critical public relations (L'Etang et al, 2016) as outlined in our introduction. We have anonymised participants, but the prefix NHS indicates quotes from NHS employees or NHS lay board members, while $\mathrm{O}$ indicates others such as local authority employees.

\section{Findings}

As noted in our introduction, although tensions between forms of citizen engagement in health services and in health research have previously been found in the literature, NHS communications as a practice has been neglected. Our findings show considerable overlap 
between communications and engagement practices and we go on to discuss the contradictory logics found within health citizenship, of engagement as public relations marketing and as an emancipatory process, showing how these are not easily separated in practice.

\section{Communications as a skill set for engagement practitioners}

Many of the staff in our sample who took responsibility for communications and/or engagement within the fast-moving STP policy had professional backgrounds in marketing and emphasised the generic nature and relevance of their communications and marketing skill set to their current NHS role.

I'm qualified more as a marketeer. ... So I think those qualifications of the marketer, because it encompasses engagement and communications and research, I think it gives you a good placing really. ' (NHS07)

Some acknowledged the distinctiveness of their public-sector role.

'In a lot of ways, it's much easier, this role, because, well, we're not trying to sell anything. ' (NHS12)

Although staff in our sample were not selling tangible goods to consumers, Malone (1999) demonstrates how policy itself may be conceptualised as a product, and we found that the narrative of the need for the NHS to transform in order to ensure sustainability and transformation was very heavily promoted. Although this participant portrayed herself as not selling, local 'buy-in' to the narrative was sought through active engagement of patients in local solutions.

We found that staff from a marketing background demonstrated a lack of awareness of emancipatory discourses and many were unfamiliar with survivor/user movements, although in their encounters with the PPI group and others, their understandings did develop. Issues faced by the NHS were sometimes viewed as similar in nature to the work of private-sector organisations looking to foster a better relationship with their customers.

I think the NHS, certainly when I joined, it was recognising that they need skills from other industries as well. ... Part of it is trying to demonstrate how marketing and communications and engagement really affects [the] bottom line, because one of the things that we're trying 
to do now is really affect contracts through person-centred outcome measures.' (NHS06)

Originally, the NHS was conceived of as a public service, rather than as an industry (Newman, 2001). Note however in the above quotation the 'equivalisation' (Fairclough, 2003) of the NHS with 'other industries'. Note also the language of the 'bottom line'-i.e. financial balance or surplus - usually associated with the private sector.

In contrast to 'marketeers', some engagement staff had long-standing experience of user involvement and participation. For example, a local authority officer, asked to explain how he did consultation, described his work with a group of disabled children as an example of good practice.

I would say consultation, generally, is - consultations where young people have been involved, and their views have been seriously considered, not taken into account in a tokenistic way. For instance, we had a consultation last year on the development of the local offer for the disabled children. ... Disabled children and young people in [location] were responsible for developing the literature, were shaping the policy and how the local offer works. That has been an outstanding example of consultation led by the people that it's affecting. All consultations should be like that.' (O21)

Despite the apparent distinction between the skill set of 'marketeer' and a more traditional userparticipation facilitator, we found discursive overlaps. For example, the notion of a public service as an 'offer', rather than a standardized service that passive citizens may be forced to accept, implies a form of citizenship that is based on a consumerist logic of choice (Newman, 2001). Nevertheless, the consultation process described appears to have shaped the content of local policy and included the voices of children and young people; a group excluded from the form of citizenship that is premised on voting for political representatives (Clarke et al, 2014). Although several 'marketeers' had no awareness of Arnstein's (1969) ladder or the politics and practice of deliberation, we found echoes of community development approaches, emphasising the importance of building relationships and honouring mutual commitments by devoting time to go out into communities to develop working relationships. Some described in detail a dialogical, responsive approach whereby inter-personal encounters developed into partnership with communities through challenge and appropriate response (Aveling and Jovchelovitch, 2014), 
'There is a man in particular that's quite influential in the area, he's an ex-councillor, very passionate about his community, and he approached us initially and said we weren't doing enough for his community. And he just said, "It's always tick box." So, we sat a long time working with him and he knows us. So, last week, I said, "We want to be coming out and talking to you about urgent care services, but it won't be me, it'll be this other team that are doing it on our part." And he was like, "No." He said, "You are not doing that," and he's pointing at me, saying, "No," he said, "You sat a long time building relationship with me and my community but you just send somebody in, I'm not having it," he says, "I want you to go in and do it." So that's how we're doing it. So, we've changed our approach and that's really key to us, that we listen to how people want to be involved with us and we tailor what we do to suit them.' (NHS12)

Staff seemed to anticipate scepticism (demonstrated in the above example in the fear of tick-box approaches) from local citizens. Listening carefully was viewed as central, and an important component of the engagement skill set:

'It's really about your disposition toward the patient, it's about genuinely listening and genuinely hearing what the patient's [saying], and giving the patient the gift of being able to credibly influence your decision making, of being flexible enough to understand a patient's perspective is not there to [...] endorse decisions you're making because you know best, it's about a genuine [...] dialogue of equals.' (NHS14)

Some participants saw no tension between relational, dialogic approaches and public relations.

'I think the NHS communicators, there is a very, very blurred line between communicating and engagement. My personal view is that you are not a particularly great communicator if you can't engage because you can't get any messages over. My major bit of my career is about public relations and public relations is essentially about relationships.' (O11)

In summary, we found that 'marketeers' were often ignorant about deliberation, had little awareness of user-emancipation and limited if any knowledge of Arnstein's ladder. They saw their expertise as deriving from their communications and public relations skill set, viewed as 
relevant for their work in the NHS. We found also that the accounts of those from a more traditional public sector PPI background included tropes of citizen-consumers.

\section{Reconciling communication and engagement in practice?}

Participants described their use of a range of approaches to engagement including a standing committee, a health bus that toured community locations, a hospital based group of 'Patient Partners', strategic use of 'experience-led commissioning', a mobile listening booth that enabled members of the public to voice opinions, use of social media, and various others. The need to balance time and resources with scope of activities was reflected in their choice of methods.

'It does depend on the type of consultation you're doing. There is an assumption-with a lot of consulters and in statutory guidance terms, it's basically acceptable [to go] digital by default: if you do an online survey and if you send something out on your webpage, that's fine. But you do also need to be appreciative that when a consultation might affect vulnerable or protected characteristics group, you do need to make sure your consultation and methodology takes that into consideration.' (O21)

Reference to 'protected characteristics' highlights legislation that confers specific rights on certain groups of individuals. The use of market segmentation techniques within the public sector, with different approaches tailored to different demographic or social groups, has been discussed by Barnett and Mahony (2016, p. 379), who note:

The increasing use of segmentation methods is indicative of the emergence of a broadly shared problematisation of public action. The defining feature of this problematisation is the idea that organisations are faced with the task of being responsive to differentiated publics while maintaining obligations of collective stake-holding or universal access.

In contrast to legalistic forms of identifying citizens, dialogic relationships with often disenfranchised communities took time to develop (Hudson, 2015). Health citizenship or engagement could also entail actively facilitating or 'brokering' interactions between clinicians and members of the public, since clinicians could be nervous when stepping outside their usual role of treating patients:

'My role is much more supportive to help them have the courage, so linking them up with groups, being that broker, that first bit and then ongoing support. [If] it is their first time, 
we will have a meeting with them beforehand, I will come along to it, and show what is available, so sort of handholding. [...] I think there is a real fearfulness that they might do the wrong thing, say the wrong thing: this is a patient, am I going to speak too much jargon? It is the unknown and actually once they meet them and I just say just have a conversation, just find out what they want from it and once you have opened that it is fine.' (NHS06)

This reference to jargon points to the relevance and skill of communications but raises the Habermasian question of how an ideal speech community might be achieved in practice (Habermas, 1989). Several participants described how they included 'quieter voices', referred to in the literature as seldom-heard, and we found some acknowledgement of the impact of social deprivation on health inequalities.

'You'll often find that in the very affluent areas, people's expectations of what they should have are significantly higher when in actual fact, the need is somewhere else. It is usually in the most deprived areas. [...] One of the responsibilities we have is to make sure that, actually, whilst you're listening to everybody, that you're not actually, not hearing the quieter voices.' (NHS16)

However, alongside the responsibility to practise inclusive engagement, participants also acknowledged that some aspects of their roles did involve seeking to present their organisations and their plans in the best light. They described the approaches they took to reconciling this more 'PR'-oriented role with their work in fostering dialogue. One engagement manager, for example, explained how he struggled to ensure that his role went beyond 'stage-managing' his hospital's 'patients' panel':

'So I'll tell you where I sit, and I tell you that it is the subject of some ongoing low-level debate within the [hospital], among professionals but more so amongst our patient group who are uncomfortable with the fact that I sit in a communications team. [...] As they see it, the objective of communications is to spin bad news into good news, and to put out a positive and -I think by inference-perhaps a slightly less transparent picture of the [hospital]. And I think they understand the situation in communications as being a 
certain stage managing of the patient group. That's not where I come from at all, and I often say to them I'm in the comms team but I'm not of the comms team.' (NHS014)

Another participant drew a distinction between the role of the communications team in general and her specific role with responsibility for PPI:

I do sit in the communications team and my role is seen as the broader management of our stakeholders, which in our directors' remit is stakeholder management and reputation management and so on and so forth. We are about reputation management, we are damage limitation. So that's where I sit, and that has caused a little friction.' (NHS02)

She referred to the expectations of people above her in the organisational hierarchy: 'And it is managing what people call our "top corridor expectations" of what we can and can't do.' (NHS02)

As this quote illustrates, whatever their personal commitment to dialogical approaches to engagement, participants found themselves in a challenging environment where other priorities could drive their work in other directions.

\section{Managing public relations: the influence of the policy context}

Many participants readily acknowledged the distinction between managing one-way communication (telling and informing) and two-way dialogue (listening and involving). They explained how organisational communication and dialogue with patients and the public could be in tension, not least because policy expectations and tight timescales for change sometimes gave them little option (cf. Author C et al., 2018):

'It is interesting I think that NHS managers will spend ages and ages consulting. And I will be testing their assumptions by saying, "Actually you are not consulting here, you are telling people. So let's not pretend, just tell them that you are going to do this. That is the honest way forward." But no, we have to wrap it up as "we are consulting on this." I think that leads to some barriers between patients and the NHS at times. I feel they [patients and the public] sense when you are actually telling them that you are going to do something, rather than asking permission to do it.' (NHS03) 
This 'wrapping up' and pretence at consultation seemed closer to the characterisation of the work of marketing professionals as spin and dishonest PR than to genuine open-ended dialogue with citizens, in which patients and the public could make a meaningful contribution to decisions (Author A et al., 2018).

As outlined in our introduction, organisations are required to demonstrate how they have sought views and responded to patients and the public when devising and revising their plans (ANON, 2018). Responsiveness to consumers is a normal part of many private-sector business models; graphic depictions of customer responsiveness, such as 'you said, we did' reports, are an increasingly common feature of the public faces of many private and public-sector organisations. Participants explained the performative nature of their practice and described the need to tangibly evidence their work of consultation and engagement, and the impact it had on organisational policy.

'And we're very clear that we will be responding to what people have said, and I think that puts a little bit of more ownership back on the commissioning manager or whoever's making the changes, so, you know, we've got to demonstrate how we've listened to this: you said, we did.' (NHS12)

Here 'ownership' of changes rests with commissioning managers. This contractual consumerist model diverges substantially from a dialogical approach and forms of involvement valorised in much of the normative academic literature on patient and public involvement. The 'you said, we did' form of responsiveness divides consultees and decision makers into separate groups operating at arm's length and reveals the contradictory logics of customer relationship marketing and models of co-production that are embedded in the messy practice of engagement.

Our analysis revealed that communications and engagement staff had a key role to play in transmitting messages to explain the Five Year Forward View (NHS England 2014) to a range of publics. We observed the process of an STP, supposedly in conjunction with a PPI group, producing a pre-consultation business case as a 'narrative' that the wider public might not only comprehend but also support (ANON 2017, ANON, 2018). A dominant message presented in such public-facing documents was the inevitable need for change, evoking the 'TINA' discourse of neoliberalism that asserts that There Is No Alternative to market-oriented reforms that radically diminish public services (Queiroz, 2018). One way in which the case for change was 
conveyed was through stories of how service changes had had a positive impact on patients. These stories or case studies were again used in a performative fashion, to demonstrate success. 'I think those who work in health are beginning to understand where we are. Public, I don't think they do. And I think it is a very hard story to tell and probably the best way to do it is through patient stories.' (NHS04)

'Potentially, every single person, every single patient treated is a case study, and the experience we could capture. [...] They've started a success board, so one of our comms and engagement team is going to go down there, spend a morning there, and hopefully will come away with some useful case studies.' (NHS05)

Notwithstanding the importance of dialogue and opportunities for patients and the public to make meaningful contributions to transformation plans, then, this work to convey a (coherent, positive) message to the public about change was an important part of the role of the communications professionals in our study. STPs were associated with a sense of urgency and thus communications and engagement staff were often forced to adopt a particular approach that sometimes meant a more distanced relationship, and more expedient, monological forms of communication, between the STP and local citizens. Approaches to managing different stakeholder groups diverged notably from the efforts described above to reducing power relationships with a view to fostering more equal dialogue.

\begin{tabular}{|l|l|l|}
\hline High Power & $\begin{array}{l}\text { Satisfy } \\
\text { Opinion formers. Keep them } \\
\text { satisfied with what is } \\
\text { happening and review your } \\
\text { analysis of their position } \\
\text { regularly }\end{array}$ & $\begin{array}{l}\text { Manage } \\
\text { Key stakeholders who } \\
\text { should be fully engaged } \\
\text { through communication and } \\
\text { consultation. }\end{array}$ \\
\hline Low Power & Monitor & $\begin{array}{l}\text { Inform } \\
\text { Patients often fall into this } \\
\text { category. It may be helpful }\end{array}$ \\
\hline
\end{tabular}




\begin{tabular}{|l|l|l|}
\hline & $\begin{array}{l}\text { This group may be ignored } \\
\text { if time and resources are } \\
\text { stretched. }\end{array}$ & $\begin{array}{l}\text { to take steps to increase their } \\
\text { influence by organising } \\
\text { them into groups or taking } \\
\text { active consultative work. }\end{array}$ \\
\hline & Low Impact Stakeholding & High Impact Stakeholding \\
\hline
\end{tabular}

Figure 1 'Prioritise your stakeholders' reproduced from NHS Improvement (undated)

Stakeholder analyses result in differentiated relationships and consequences flow for citizens and other stakeholders. Such analyses typically plot two axes to produce a two-by-two grid. Communications staff explained how a stakeholder map determined their methods and the amount of time they could devote to engagement with these various groups.

'We'd do a stakeholder map. So, it will be things like ... interests and influence. So what is their likely interest? What is their influence? And that will dictate to us how much time we spend and what sort of method of engagement we would undertake.' (NHS12)

We reproduce an instance of such a grid from NHS Improvement (undated) (Figure 1). Themes of power, interest and influence were explicit in a stakeholder analysis carried out by one NHS organisation involved in one of the programmes in our case study, and recorded in a table comprising six stakeholder groups, including members of the public, patients and carers and representative groups (including 'Seldom Heard Groups'), internal stakeholders, commissioning partner organisations and 'opinion formers' that included media and local MPs. The document coded each stakeholder according to their perceived level of power and influence, low to high, and this was mapped against an axis of their level of interest, also from low to high. Local patient groups, organisations and charities were coded as 'high interest / low influence'. These groups thus appear to be regarded as relatively powerless. In contrast, stakeholders categorised as having 'high influence and high interest' included MPs, local media and other organisations in the local health economy. Examples of completed stakeholder analyses are rarely found in the public domain, presumably as they are highly sensitive internal organisational documents, but we found that communications staff were very aware of these as part of their professional role. Models whereby those with low power and influence are given the least attention precisely invert 
Arnstein's (1969, p. 216) analysis of policy that, rhetorically at least, aimed at 'maximum feasible participation of the poor'. In contrast to empowerment of the seldom-heard and a commitment to reduce health inequalities, stakeholder analyses pay most attention to the powerful, thereby endorsing the status quo.

As we see above, at least some of our participants saw their role in wider terms than simply keeping the public informed and quiescent through one-way communication. However, any commitment they had to more inclusive and dialogical forms of public engagement was tempered by their awareness of the wider political-economic context, including the pressing need for change driven by pressures on local organisations from NHS England and NHS Improvement (Edwards, 2016). Even as he invoked Arnstein's (1969) ladder of participation, one engagement manager acknowledged that in practice, he had to 'neutralise' it to ensure fit with the expectations of his organisation:

'In the PPI strategy when you see it, you will see a hacked approximation of Arnstein's ladder of participation, just to try and convince the board that the ultimate goal is empowerment-but actually, it's modified and neutralised a little.' (NHS14)

This modification and neutralising process echoes the bottom rungs of Arnstein's ladder 'manipulation' and 'therapy'. It appears that, alongside proficiency in participation and consultation methods, engagement staff are experts in others forms of PR, including communicating convincing messages and narratives to board members and other powerful stakeholders.

Discussion and conclusion

Our analysis identified a range of engagement modalities from digital surveys to a PPI engagement group, all of which might be characterised as forms of health citizenship. Citizenship, as Clarke et al (2014:176) discuss, is an unsettled notion; these authors insist on particularity rather than abstraction thus:

\footnotetext{
While citizenship has sedimented associations with equality, difference, rights, democracy and participation, the meaning of these terms is always particular, subject to revision and reworking. The substance of any of them - and their mutual articulation remains the focus of political-cultural conflicts.
} 
Situating our data within the particular policy context, we show how practitioners operate within the interstices of organisational and inter-organisational constraints. Scholars of critical public relations and sociologists alike have voiced concerns that managerialist approaches to patient and public involvement may do little more than provide a rationalising veneer of organisational impression management that glosses over citizens' rights to participate in policy and politics (Fotaki, 2011, L'Etang et al, 2016, Author C, 2012). Accordingly, a reductive analysis might caricature the role of comms specialists as solely one of 'spinning' bad news into good, or of framing transformation changes in a way that will be more appetising to the public. However, our focus on the detail of engagement practices, and the conflicting logics and locations that engagement practitioners must negotiate, provides a more nuanced understanding of constraints on practice and the technologies associated with communications and public relations. Within the NHS as elsewhere, 'engagement' encompasses a wide variety of approaches (Dalton et al. 2015). These staff not only relate to citizens but to other stakeholders, many of whom fall into the high power, high 'stakeholding' quadrant of the matrix (Figure 1). Staff must negotiate 'top corridor' demands, for example to ensure damage limitation, manage stakeholders that include politicians, and they may need to be aware of local media. Resource constraints also affect the operationalisation of otherwise vague imperatives to engage, and, while relationship building may traditionally be considered a face to face activity, different methods such as digital surveys may be required to engage a large number of citizens in a short space of time.

Many communications and engagement practitioners in our study claimed to embrace and endorse dialogue as a way of securing effective engagement and explained how facilitating such dialogue in ways that overcame paternalistic / deferential relationships was a key part of their skill set. Notwithstanding their different backgrounds, and in some cases, their relative lack of knowledge about user-led movements, many staff professed commitment to empowerment of a range of citizens, including those ineligible to vote and the 'seldom heard'. Indeed, the communications skill set might have an important contribution to make to efforts to equalize power relationships between patients and staff, to explain incomprehensible jargon and facilitate meaningful involvement exercises that go beyond 'technologies of legitimation' (Harrison and Mort 1997). Such a challenge to professional power is, of course, in line with a managerialist agenda, but it can also serve a more emancipatory purpose, as we saw in examples of involving young citizens and listening to seldom heard voices. 
Nonetheless, this was not the only work that staff undertook as they engaged citizens in the work of the STP. Their work also encompassed what is sometimes seen as the 'darker' side of public relations (Moloney, 2006), including using the views derived from the public in a more instrumental way, to provide justification for pre-planned changes and decisions which were effectively already made. Moreover, the political-economic context of the current English NHS meant that participants often prioritised this part of their role, acknowledging that dialogical approaches sometimes were put aside and replaced by activities such as 'you said, we did' exercises based on more consumerist models of the relationship between the NHS and its public. Consulting with those who share protected characteristics raises the thorny issue of representation familiar to researchers in this field (Author C, 2008) and reliance on 'digital-bydefault' surveys risks cursory or 'tick box' involvement, of the kind identified by Arnstein as therapy or manipulation (Arnstein, 1969). Cornwall and Gaventa (2000) have drawn attention to the distinction between passive 'users', consumerist 'choosers' and democratic models of involvement whereby people are encouraged to participate in policy as 'makers and shapers'. A key difference between consumerist models of 'using' and 'choosing', and more emancipatory, participatory approaches, is that the latter allow citizens to express legitimate dissent, participate in ongoing dialogue and exert influence as they make and shape policy. As Bauman (1995: 273) has written, constituting the citizen merely as 'user' or 'chooser' renders her/him

not $[\ldots]$ a person eager to assume responsibility for issues larger than his private needs and desires, but as a consumer of services provided by agencies s/he has little right and no interest to examine, let alone supervise. Citizens' charters promote that image of the citizen by defining citizens' rights as first and foremost, perhaps even solely, the right of the customer to be satisfied. This includes the right to complain and to compensation. This does not include, conspicuously, the right to look into the inner workings of the agencies complained about and expected to pay the compensation - much less the right to tell them what to do and according to what principles.

Lack of transparency blocked citizens from viewing STPs' 'inner workings'(Alderwick et al., 2016). The risk of regarding policy as an already finished product to be effectively communicated or 'sold' to 'stakeholders' is that the most powerful stakeholders are allocated the most time and attention. Communicating a predetermined narrative means that policy is 
depoliticized rather than negotiated in dialogue (Malone, 1999), persuading citizens that there is no alternative to the planned proposals (Queiroz, 2018).

We have demonstrated how practitioners articulate competing logics of public relations in contradictory ways. Where communications and engagement staff 'sit' as they engage consumers, citizens, patients and the public, appears to be a somewhat uncomfortable liminal location. We found that, at a time of organisational turbulence, communications staff were respectful towards patients and the public and recognised their need for clear, timely information in a range of formats. We also found, however, that practice was often driven by the need to manage organisational reputations, ensure damage limitation and communicate pre-defined policy in top-down fashion. Public relations appears to function as one modality of health citizenship and we conclude that, at a time of persistent health inequalities, when founding principles of the NHS are under threat (Exworthy et al, 2016), unequal attention is paid to powerful stakeholders.

\section{References}

Alderwick H, Dunn P, McKenna H et al. (2016) Sustainability and transformation plans in the NHS. London: King's Fund.

Arnstein SR (1969) A ladder of citizen participation. Journal of the American Institute of Planners 35(3): 216-224.

Author A (2012)

Author A et al. (2018)

Author B et al. (2015)

Author C (2008)

Author C (2012)

Author C et al. (2017)

Author C et al. (2018)

Aveling EL and Jovchelovitch S (2014) Partnerships as knowledge encounters: a psychosocial theory of partnerships for health and community development. Journal of health psychology, Vol. 19 No.1, p. 34-45.

Baggott R (2013) Partnerships for Public Health and Well-Being: Policy and Practice. Basingstoke: Palgrave Macmillan. 
Barnes M, Newman J, and Sullivan H (2007) Power, Participation and Political Renewal: Case Studies in Public Participation. Bristol: Policy Press.

Barnett C and Mahony N (2016) Marketing practices and the reconfiguration of public action. Policy \& Politics 44(3): 367-382.

Bauman Z (1995) Life in Fragments: Essays in Postmodern Morality. Oxford: Blackwell.

Bovaird T and Loeffler E (2012) From engagement to co-production: The contribution of users and communities to outcomes and public value. Voluntas: International Journal of Voluntary and Nonprofit Organizations 23(4): 1119-1138.

Clarke, J., Coll, K., Dagnino, E., \& Neveu, C. (2014). Disputing citizenship. Policy Press.

Cole M and Cotterill L (2005) UK health action zones: political accountability and political marketing-perspectives from the South West. Urban Studies 42(3): 397-416.

Cornwall A and Gaventa J (2000) From users and choosers to makers and shapers repositioning participation in social policy. IDS Bulletin 31(4): 50-62.

Dalton J, Chambers D, Harden M et al. (2015) Service user engagement and health service reconfiguration: a rapid evidence synthesis. Health Services and Delivery Research 3(17).

Department of Health (2012) Liberating the NHS: No Decision about Me, Without Me: Government Response. London: Department of Health.

Edwards N (2016) Sustainability and Transformation Plans: What We Know So Far. London: Nuffield Trust.

Exworthy M, Mannion R and Powell M (2016) Dismantling the NHS? Evaluating the Impact of Health Reforms. Bristol: Policy Press.

Fairclough N (2003) Analysing Discourse: Textual Analysis for Social Research. London: Routledge.

Fotaki M (2011) Towards developing new partnerships in public services: users as consumers, citizens and/or co-producers in health and social care in England and Sweden. Public Administration 89(3): 933-955.

Francis R (2013) Report of the Mid Staffordshire NHS Foundation Trust Public Inquiry. London: The Stationery Office.

Gewirtz S, Dickson M and Power S (2004) Unravelling a 'spun' policy: A case study of the constitutive role of 'spin' in the education policy process. Journal of Education Policy 19(3): 321-342.

Gibson A, Britten N and Lynch J (2012) Theoretical directions for an emancipatory concept of patient and public involvement. Health 16(5): 531-547. 
Habermas J (1989) The Structural Transformation of the Public Sphere: An Inquiry into a Category of Bourgeois Society. Cambridge: Polity.

Harrison S and Mort M (1998) Which champions, which people? Public and user involvement in health care as a technology of legitimation. Social Policy \& Administration 32(1): 60-70.

Hogg C (1999) Patients, Power \& Politics: From Patients to Citizens. London: Sage.

Hudson B (2015) Public and patient engagement in commissioning in the English NHS: An idea whose time has come? Public Management Review 17(1): 1-16.

Hunter DJ (2010) The slow, lingering death of the English NHS. International Journal of Health Policy and Management 5(1): 55-57.

James J (2013) Health policy brief: patient engagement. Available at

https://www.healthaffairs.org/do/10.1377/hpb20130214.898775/full/healthpolicybrief 86.pdf(ac cessed 3 January 2018).

King's Fund (2012) Leadership and engagement for improvement on the NHS. Available at https://www.kingsfund.org.uk/sites/default/files/field/field publication file/leadership-forengagement-improvement-nhs-final-review2012.pdf (accessed 3 January 2018).

Komporozos-Athanasiou A, Fudge N and McKevitt C (2018) Citizen participation as political ritual: Towards a sociological theorizing of 'health citizenship'. Sociology in press.

Kvale S (2008) Doing Interviews. London: Sage.

Law J (2004) After Method: Mess in Social Science Research. London: Routledge

Leys C (2017) The English NHS: from market failure to trust, professionalism and democracy. Soundings 64: 11-40.

Madden M and Speed E (2017) Beware zombies and unicorns: Toward critical patient and public involvement in health research in a neoliberal context. Frontiers in Sociology 2(7).

Malone RE (1999) Policy as product: morality and metaphor in health policy discourse. Hastings Center Report 29(3): 16-22.

Moloney K (2006) Rethinking Public Relations. London: Routledge.

Moor L (2011) Neoliberal experiments: Marketing and the governance of populations. In Zwick D and Cayla J (eds) Inside Marketing. Oxford: Oxford University Press, pp.299-319.

Mouffe C (2005) On the Political. Abingdon, Routledge.

Newman J (2001) Modernising Governance: New Labour, Policy and Society. London: Sage.

NHS England (2013a) The NHS belongs to the people: a call to action. Available at https://www.england.nhs.uk/2013/07/call-to-action/ (accessed 3 January 2018). 
NHS England (2013b) Planning and Delivering Service Changes for Patients. Leeds: Department of Health.

NHS England (2014) Five Year Forward View. Available at https://www.england.nhs.uk/wpcontent/uploads/2014/10/5yfv-web.pdf (accessed 3 January 2018)

NHS England (undated a) Ladder of engagement. Available at https://www.england.nhs.uk/participation/resources/ladder-of-engagement-2/ (accessed 7 December 2017).

NHS England (undated b) Putting the patient first: the NHS England business plan for 2013/142015/16. Available at https://www.england.nhs.uk/wp-content/uploads/2013/04/ppf-13141516.pdf (accessed 11 December 2017).

NHS Improvement (undated) https://improvement.nhs.uk/documents/2169/stakeholderanalysis.pdf accessed August 22018

Parsons S, Winterbottom A, Cross P et al. (2010) The Quality of Patient Engagement and Involvement in Primary Care. London: Kings Fund.

Peters BG (2016) Governance and the media: exploring the linkages. Policy \& Politics 44(1): 922.

Potter J (1996) Discourse, Rhetoric and Social Construction. London: Sage.

Ramsey P (2016) The public sphere and PR: deliberative democracy and agonistic pluralism. In L'Etang J, McKie D, Snow N and Xifra J (eds) The Routledge Handbook of Critical Public Relations. Routledge: Abingdon, pp.65-75.

Queiroz R (2018) Neoliberal TINA: an ideological and political subversion of liberalism. Critical Policy Studies in press.

Tritter JQ and McCallum A (2006) The snakes and ladders of user involvement: moving beyond Arnstein. Health Policy 76(2): 156-168.

Walsh K (1994) Marketing and public sector management. European Journal of Marketing 28(3): 63-71. 